The Bangladesh V eterinarian (2016) 33(2) : 33 - 38

\title{
Factors influencing the pregnancy rate in indigenous ewes following Al using frozen semen
}

\author{
N N aher*, N S Juyena, PK Jha, M RI Talukder, M G S Alam and FY Bari \\ Department of Surgery and Obstetrics, Faculty of Veterinary Science, Bangladesh \\ Agricultural University, Mymensingh-2202, Bangladesh
}

\begin{abstract}
Study was conducted to observe the influence of different factors on pregnancy rate in 24 indigenous ewes following artificial insemination (AI) with frozen semen. The ewes were synchronized by intra-muscular injection of Prostaglandin $F_{2} a$ (Ovuprost ${ }^{\circledR}$ Bayer, New Zealand). The onset and intensity of oestrus were determined by oestrus behaviour of ewes with vasectomized ram. VER values were measured immediately before Al using electrical heat detector (DRAMINSKI ${ }^{\circledR}$, Owocowa 17, Poland). Twelve ewes were inseminated trans-cervically and 12 laparoscopically. Five ewes were treated with Misoprostol (Cytomis ${ }^{\circledR} 200 \mu \mathrm{g}$ tablet; Incepta Pharmaceuticals Ltd. Bangladesh) to relax the cervix 12 hours before TCAI, and cervical penetration depth was measured by a steel rod. Pregnancy was confirmed by ultrasonography at 40 - 45 days after Al. Cervical penetration depth was significantly increased $(P \varangle 0.05)(0.48 \pm 0.04$ vs. $3.52 \pm 0.17 \mathrm{~cm})$ in treatment group. The pregnancy rate tended to be higher in treatment group (60.0 vs. $28.6 \%)$. In treatment group cervical penetration was significantly increased $(P<0.05)(0.35 \pm$ 0.08 vs. $3.52 \pm 0.17 \mathrm{~cm})$ immediately before Al compared with before oestrus synchronization. The pregnancy rate was significantly higher $(\mathrm{P} \varangle 0.05)(75.0 \mathrm{vs.} 28.6 \%)$ in LAPAI than TCAI without treatment. The pregnancy rate tended to be higher (75.0 vs. $55.6 \%)$ in ewes with high oestrus intensity than in those with medium intensity. The pregnancy rate was significantly higher ( $P \varangle 0.05: 70.0$ vs. $20.0 \%$ ) in lower VER group (230 $280 \Omega$ ) compared with higher VER group (331 - $380 \Omega$.) Although LAPAI was superior to TCAI, TCAI in ewes treated with misoprostol giving a pregnancy rate of $60 \%$ could be acceptable, until the LAPAI could be made simpler to be used in field. The oestrus intensity and low VER values could be used to select ewes to be inseminated to increase the pregnancy rate. (Bangl. vet. 2016. Vol. 33, No. 2, 33 -38)
\end{abstract}

\section{Introduction}

Indigenous sheep are not ideally productive due to poor genetic merit (Rahman, 2005). There is a scarcity of high quality breeding rams in Bangladesh. This problem can be overcome by Artificial insemination (AI) (Meat New Zealand, 2002). The widespread use of Al depends on the use of frozen semen and acceptable fertility. Trans-cervical insemination (TCAI) could be the most convenient practice but it is challenging to pass an inseminating pipette through ovine cervix due to its complicated nature (Leethongdee, 2009). To overcome this problem, cervix needs to

*Corresponding author:- E-mail: nazmun_naher_bau@yahoo.com 
be relaxed to allow deeper penetration by the inseminating pipette through the cervical folds (Leethongdee, 2011) or the cervix can be bypassed through laparoscopic artificial insemination (LAPAI) (Hiwas et al., 2009). Intensity of oestrus and Vaginal Electrical Resistance (VER) are considered as important factors influencing pregnancy rate (Kozdrowski et al., 2006; Garcia et al., 2011). The main objectives of this study were to develop the TCAI through increasing cervical penetration depth and improve LAPAI to increase pregnancy rate, and to determine effects of induced oestrus intensity and vaginal electrical resistance (VER) on pregnancy rate of indigenous ewes using AI with frozen semen.

\section{M aterials and M ethods}

\section{Animal selection}

A total of 24 healthy non-pregnant indigenous ewes were selected from the research project of Bangladesh Academy of Sciences - The United States Department of Agriculture (BAS - USDA) at the Department of Surgery and Obstetrics, Faculty of Veterinary Science, Bangladesh Agricultural University, Mymensingh-2202.

\section{O estrous synchronization}

The ewes were synchronized for oestrus using two intra-muscular injections of Prostaglandin $\mathrm{F}_{2} \mathrm{a}$ (Ovuprost ${ }^{\circledR}$ Bayer, N ew Zealand) at the rate of $125 \mu \mathrm{g}(0.5 \mathrm{~mL})$ per ewe at an interval of 9 days. Oestrus was detected using vasectomized ram by observing behavioural signs from 6 am to $6 \mathrm{pm}$.

\section{O bservation of oestrus intensity}

The intensity of oestrus was graded as low, medium or high as described by Ortman (2000).

\section{Vaginal Electrical Resistance (VER) recording}

VER of ewes were measured immediately before Al by inserting the probe of electrical heat detector (DRAMINSKI ${ }^{\circledR}$, Owocowa 17 , Poland) into vagina as described by Theodosiadou and Tsiligianni (2015).

\section{Cervical relaxation treatment}

Following synchronization, the ewes $(n=5)$ were treated with prostaglandin E1 analogue Misoprostol (Cytomis ${ }^{\circledR} 200 \mu \mathrm{g}$ tablet; Incepta Pharmaceuticals Ltd. Bangladesh) @ $400 \mu \mathrm{g}$ per ewe intra-vaginally. Following grinding and mixing of Cytomis with glycerol (glycerol approximately 87\%, Merck), the mixture was embedded in a sterile piece of sponge. The medicated sponge was then inserted just in front of cervical opening i.e. caudal to the cervix and removed after $12 \mathrm{hrs}$. 


\section{Cervical penetration depth measurement}

Cervical penetration depth was measured just before insemination by introducing a steel rod of $25 \mathrm{~cm}$ length, $0.25 \mathrm{~cm}$ diameter, having round end (Modification of Leethongdee et al., 2011) into the cervix.

\section{Post-thaw semen evaluation}

The quality of thawed semen was assessed by percentage motility, viability and plasma membrane integrity of the sperm. Motility was observed by phase-contrast microscope at magnification of $400 \times$ and the viability and plasma membrane integrity were assessed by eosin-nigrosin stain and hypo-osmotic swelling test (HOST +ve), respectively.

\section{Trans-cervical artificial insemination (TCAI)}

Trans-cervical artificial insemination (TCAI) (without and with cervical relaxation treatment) was performed in 12 ewes within $14-20$ hours of onset of oestrus using frozen semen of indigenous ram having $49.0 \pm 4.2,62.0 \pm 4.9$ and $55.0 \pm 8.1 \%$ postthaw motility, viability and HOST +ve\% with the aid of a commercially available insemination pipette with a sharp pointed bent tip, especially designed for TCAI of ewes (eccentric insemination pipette for Sheep/ Goat; Minitube, Slovakia).

\section{Laparoscopic artificial insemi nation (LAPAI)}

Seven ewes were inseminated laparoscopically within 20 - 24 hours of onset of oestrus using a commercially available insemination pipette (Robertsone pipette standard for Laparoscopic Al in sheep with tube, Minitube, Slovakia). The abdomen was punctured in two places simultaneously, for LA PAI tube and AI pipette.

\section{Pregnancy diagnosis}

Ultrasonography scanning was done for confirmation of pregnancy using transabdominal ultrasonic transducer 5.0 MHz (Model Magic 5000, Art NO. 303700, Germany) 40 - 50 days post insemination.

Pregnancy rate $(\%)=$ N umber of ewes concei ved $\times 100$ / N umber of ewes inseminated.

\section{Statistical analyses}

The collected data were analyzed using SPSS 20.0. Comparison of cervical penetration was done using t test. Chi-square test was performed to compare the pregnancy rate. When the $P$ value was less than $0.05(P \varangle 0.05)$, the difference was regarded as significant.

\section{Results and Discussions}

\section{Effects of cervical relaxation treatment on pregnancy rate}

The effects of cervical relaxation treatment on pregnancy rate are shown in Table 1. The cervical penetration of the group without treatment and with Misoprostol 
treatment was $0.37 \pm 0.10$ and $0.35 \pm 0.08 \mathrm{~cm}$ immediately before oestrous synchronization. The measurement was $0.48 \pm 0.04$ and $3.52 \pm 0.17 \mathrm{~cm}$ immediately before AI. The penetration depth was significantly higher $(\mathrm{P}<0.05)$ in treatment group than non-treatment group, and after treatment than before. The increased penetration in treated group allowed the semen to be deposited deep in the cervix, which might result in higher pregnancy rates (60.0 vs. $28.6 \%$ ) compared with non-treatment group. Salmon and Maxwell (1995) stated that the greater cervical penetrability of sperm could ensure the success of TCAI with higher pregnancy rate. Since PGEl analogue (misoprostol) causes softening of cervix and dilatation of cervical lumen, the semen can be deposited beyond $3 \mathrm{~cm}$, which resulted in higher pregnancy rate (Leethongdee, 2011). Rashidi and Cedden (2013) found $68.2 \%$ pregnancy rate following administration of misoprostol, similar to our result.

Table 1: Depth of cervical penetration before and after cervical relaxation treatment and pregnancy rate following TCAI

\begin{tabular}{l|c|c|c|c|c}
\hline \multicolumn{1}{c|}{ Groups } & $\begin{array}{c}\text { Dose } \\
\text { of } \\
\text { drug }\end{array}$ & $\begin{array}{c}\text { No. of } \\
\text { ewes }\end{array}$ & $\begin{array}{c}\text { Depth of cervical } \\
\text { penetration before } \\
\text { oestrus synchronization } \\
\text { (cm) (Mean } \pm \text { SE) }\end{array}$ & $\begin{array}{c}\text { Depth of cervical } \\
\text { penetration } \\
\text { immediately before Al } \\
\text { (cm) (M ean } \pm \text { SE) }\end{array}$ & $\begin{array}{c}\text { Pregnancy } \\
\text { rate (\%) }\end{array}$ \\
\hline $\begin{array}{l}\text { Without } \\
\text { treatment }\end{array}$ & N/A & 7 & $0.37 \pm 0.10^{\mathrm{b}}$ & $0.48 \pm 0.04 \mathrm{~b}$ & $(2 / 7)$ \\
$\begin{array}{l}\text { Treatment with } \\
\text { misoprostol }\end{array}$ & $400 \mu \mathrm{g}$ & 5 & $0.35 \pm 0.08^{\mathrm{b}}$ & $3.52 \pm 0.17 \mathrm{a}$ & $(3 / 5)$ \\
\hline
\end{tabular}

Values with different superscripts indicate significant difference of cervical penetration between columns and rows $(\mathrm{P} \varangle 0.05)$

\section{Effects of methods of Al on pregnancy rate in indigenous ew es using frozen semen}

The pregnancy rate following different methods of Al is shown in Table 2. The pregnancy rate was significantly higher $(\mathrm{P} \varangle 0.05)(75.0 \mathrm{vs.} 28.6 \%)$ in LAPAI than TCAI without cervical relaxation treatment. However, the pregnancy rate was nonsignificantly higher after LAPAI $(75.0$ vs. $60.0 \%)$ than after TCAI with cervical relaxation treatment. LAPAI bypasses the cervix and deposits semen directly into uterine horn (Fukui et al., 2010). These findings conform to the study of Hiwas et al. (2009) who found $70 \%$ pregnancy rate.

Table 2: Effects of methods of AI on pregnancy rate

\begin{tabular}{l|c|c|c}
\hline \multicolumn{1}{c|}{ Methods of AI } & $\begin{array}{c}\text { No. of ewes } \\
\text { inseminated }\end{array}$ & $\begin{array}{c}\text { No. of ewes } \\
\text { pregnant }\end{array}$ & $\begin{array}{c}\text { Pregnancy rate } \\
\text { (\%) }\end{array}$ \\
\hline TCAI (without cervical relaxation treatment) & 7 & 2 & $28.6^{\circ}$ \\
TCAI (cervical relaxation with misoprostol) & 5 & 3 & $60.0^{\mathrm{a}}$ \\
LAPAI & 12 & 9 & $75.0^{\mathrm{a}}$ \\
\hline
\end{tabular}

Values with different superscripts indicate significant difference $(P \nless 0.05)$ 


\section{Effects of oestrus intensity on pregnancy rate}

The effects of oestrus intensity on pregnancy rate are presented in Table 3 . The pregnancy rate tended to be higher $(75.0$ vs. $55.6 \%)$ in ewes with high oestrus intensity compared with medium oestrus intensity. No ewe became pregnant which exhibited low oestrus intensity. High concentration of oestradiol during oestrus, reduces uterine $\mathrm{pH}$, which decreases sperm motility and metabolism. As a result, the viability and permanence of sperm in the female reproductive tract increases, favouring fertilization (Ferraz et al., 2017). This may be the reason why ewes with high oestrus intensity had higher pregnancy rate. The finding of our study is consistent with the study of Ferraz et al. (2017) who found higher pregnancy rate after high intensity of oestrus expression.

Table 3: Effects of oestrus intensity on pregnancy rate

\begin{tabular}{l|c|c|c|c}
\hline Oestrus intensity & $\begin{array}{c}\text { No. of ewes } \\
\text { inseminated }\end{array}$ & $\begin{array}{c}\text { No. of ewes } \\
\text { pregnant }\end{array}$ & Pregnancy rate (\%) & \\
\hline High & 12 & 9 & 75.0 & NS \\
Medium & 9 & 5 & 55.6 & NS \\
\hline
\end{tabular}

NS indicates non-significant; $(P>0.05)$

\section{Effects of vaginal electrical resistance (VER ) on pregnancy rate}

The effects of VER on pregnancy rate are presented in Table 4. The pregnancy rate was significantly higher $(P<0.05)(70.0$ vs. $20.0 \%)$ in VER group $230-280 \Omega$ compared with VER group $331-380 \Omega$. Accurate oestrus detection and appropriate timing of $\mathrm{Al}$ is important for obtaining high pregnancy rate (Yamauchi et al., 2009). The lowest value of VER might be a useful tool for oestrus detection and determining appropriate time of Al, as the lowest impedance of vaginal mucous membrane occurs when oestrogen concentration peaks (Yamauchi et al., 2009). The finding of this study is in agreement with the study of Theodosiadou and Tsiligianni (2015) who reported that ewes inseminated with low electrical resistance of cervical mucus (ERCM) $<300 \Omega$ had higher pregnancy rate than those with high ERCM.

Table 4: Effects of Vaginal Electrical Resistance (VER) on pregnancy rate

\begin{tabular}{l|c|c|c}
\hline $\begin{array}{c}\text { Vaginal electrical resistance } \\
(\text { VER }(\Omega)\end{array}$ & $\begin{array}{c}\text { No. of ewes } \\
\text { inseminated }\end{array}$ & $\begin{array}{c}\text { No. of ewes } \\
\text { pregnant }\end{array}$ & $\begin{array}{c}\text { Pregnancy rate } \\
(\%)\end{array}$ \\
\hline $230-280$ & 10 & 7 & $70.0^{\mathrm{a}}$ \\
$281-330$ & 9 & 6 & $66.7^{\mathrm{a}}$ \\
$331-380$ & 5 & 1 & $20.0^{\mathrm{b}}$ \\
\hline
\end{tabular}

Values with different superscripts differ significantly $(P \varangle 0.05)$

\section{Acknowledgments}

The authors are grateful to Bangladesh Academy of Sciences- The United States Department of Agriculture (BAS-USDA) (LS-02) for financial support. 


\section{References}

Ferraz PA, Loiola MV, Rodrigues AS, Lima MC, Bittencourt TC, Ribeiro Filho AD 2017: The effect of the intensity of estrus expression on the follicular diameter and fertility of Nellore cows managed under a FTAI program. Ciência A nimal Brasileira 18.

Fukui Y, Kohno H, Okabe K, Katsuki S, Yoshizawa M, Togari T, Watanabe H 2010: Factors affecting the fertility of ewes after intrauterine insemination with frozen-thawed semen during non-breeding season. Journal of Reproduction and Development $\mathbf{5 6}$ 460-466.

Garcia E, Hultgren J, Fällman P, Geust J, Algers B, Stilwell G, Gunnarsson S, RodriguezMartinez H 2011: Oestrous intensity is positively associated with reproductive outcome in high-producing dairy cows. Livestock Science 139 191-195.

Hiwasa M, Kohno H, Togari T, Okabe K, Fukui Y 2009: Fertility after different artificial insemination methods using a synthetic semen extender in sheep. Journal of Reproduction and D evelopment 55 50-54.

Kozdrowski R, Twardoń J, Dejneka GJ, Dzięcioł M 2006: Influence of oestrus intensity and level of physical constitution on results of artificial insemination in cattle. M edycyna W eterynaryjna 62 1038-1040.

Leethongdee S 2009: Development of trans-cervical artificial Insemination in sheep with special reference to anatomy of cervix. Suranare J ournal of Science and Technology $\mathbf{1 7}$ 57-69.

Leethongdee S 2011: Induction of Cervical Relaxation for Artificial Insemination in Sheep. Thai Journal of V eterinary M edicine 41 403-407.

Meat New Zealand 2002: Improving the success rate of artificial insemination (AI) of sheep, R \& D Brief \# 95, A Project report, funded by Meat New Zealand and the Foundation for Research, Science and Technology. www.meatnz.co.nz (go to 'farming') and quote $R \& D$ Brief 95 .

Ortman R 2000: Monitoring of estrus cycle of ewes by ram-seeking behavior. Small Ruminant Research 37 73-84.

Rahman MH 2005: National Livestock Policy Document: Dairy Development and Meat Production. FAO, Dhaka, Bangladesh.

Rashidi M, Cedden F 2013: Trans-cervical artificial insemination in ewes during out of breeding season. M acedonian Journal of A nimal Science 3 143-146.

Theodosiadou E, Tsiligianni T 2015: Determination of the proper time for mating after oestroussynchronisation during anoestrous or oestrous by measuring electrical resistance of cervical mucus in ewes. V eterinarni M edicina 60 87-93.

Yamauchi S, Nakamura S, Yoshimoto T, Nakada T, Ashizawa K, Tatemoto H 2009: Prediction of estrous cycle and optimal insemination time by monitoring vaginal electrical resistance (VER) in order to improve the reproductive efficiency of the Okinawan native Agu pig. A nimal Reproduction Science 113 311-316. 